\title{
TEACHER PERCEIVED IMPACT OF TECHNOLOGY ON ELEMENTARY CLASSROOMS AND TEACHING
}

Connie M. Crane

Dr. Dan Cockrell

Dr. Jerry Valentine
Dissertation Supervisor

Dissertation Supervisor

\begin{abstract}
Issues surrounding technology integration are varied. Over the last decade, the presence of technology in elementary classrooms has increased; however, research indicates that many teachers are not utilizing these resources effectively. Although research supports the notion that technology in the classroom has an influence on student learning, research also points to the teacher as an important lynch pin in technology integration in the curriculum (Mandell, Sorge, \& Russell, 2002).

The purpose of this study was to investigate how technology is used and integrated into the elementary curriculum and to explore the influence of technology on student success. The study focused primarily on the teachers' knowledge and skill levels in using and integrating technology into the curriculum and on professional development opportunities in the area of technology use and integration provided to teachers. Using a mixed method comparative design, data were generated from teacher surveys and focus group and individual interviews.

Data from the survey questionnaire were analyzed using descriptive statistics. A t-test was used to determine if there was a significant difference between the groups of teachers, including those from a non-technology school and those from a technology school who teach in non-technology and technology classrooms. Focus group and
\end{abstract}


individual interview data were analyzed in order to identify patterns and topics of belief, values, and practices related to the teachers' classroom technology use.

The two schools in this study were an elementary school (technology school) that has an intensive technology program (eMINTS) and another elementary school (nontechnology school) that does not have an intensive technology program. The following subgroups of teachers from the schools were included in the study:

a) teachers in grades K-3 of both schools

b) teachers in the non-technology school grades 1-3 and Non-eMINTS teachers in the technology school K-6

c) teachers in the non-technology school grades 1-3 and teachers in the eMINTS program grades 3-6

d) teachers in the technology school grades 3-6 that were eMINTS teachers and teachers in the same school grades K-6 that were not eMINTS teachers.

The findings revealed significant differences between teachers' perceptions of their roles and responsibilities for integrating technology, the influence of technology on student success, and the type of professional development activities conducted. With the eMINTS grades 3-6 versus Non-eMINTS grades K-6 analysis at the technology school, there was a significant difference in beliefs and reality of the teachers. Non-eMINTS teachers perceived greater external pressure to use and integrate technology in the classroom; whereas, the eMINTS teachers in grades 3-6 identified a greater ideology about, competence level in, and resources available for technology. Differences in perceptions about professional development were also found. 
Qualitative findings for this study revealed three primary themes that appear to be essential to understanding the use and integration of technology in elementary classrooms and the influence of technology on student success. Those primary themes include: (1) barriers to technology integration; (2) importance of technology training; and (3) learning environment. 